\title{
Dissecting the predictive value of MAPK/AKT/estrogen-receptor phosphorylation axis in primary breast cancer to treatment response for tamoxifen over exemestane: a Translational Report of the Intergroup Exemestane Study (IES) —PathIES
}

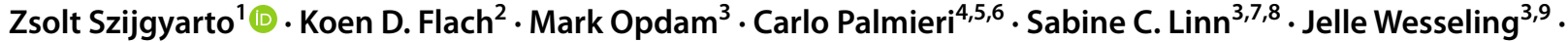 \\ Simak Ali $^{6}$. Judith M. Bliss ${ }^{1} \cdot$ Maggie Chon U. Cheang ${ }^{1} \cdot$ Wilbert Zwart $^{2} \cdot$ R. Charles Coombes ${ }^{6}$
}

Received: 3 October 2018 / Accepted: 18 December 2018 / Published online: 24 January 2019

(c) The Author(s) 2019

\begin{abstract}
Purpose The prognostic and predictive values of the MAPK/AKT/ER $\alpha$ phosphorylation axis (pT202/T204MAPK, pT308AKT, pS473AKT, pS118ER $\alpha$ and pS167ER $\alpha$ ) in primary tumours were assessed to determine whether these markers can differentiate between patient responses for switching adjuvant endocrine therapy after 2-3 years from tamoxifen to exemestane and continued tamoxifen monotherapy in the Intergroup Exemestane Study (IES).

Methods Of the 4724 patients in IES, 1506 were managed in a subset of centres $(N=89)$ participating in PathIES. These centres recruited $1282(85 \%, 1282 / 1506)$ women into PathIES of whom 1036 had phospho-marker data. All phospho-markers were analysed by immunohistochemistry staining. Multivariable Cox proportional hazards models of the phospho-markers for disease-free survival (DFS) and overall survival (OS) were adjusted for clinicopathological factors. Treatment effects on the biomarker expression were determined by interaction tests. Benjamini-Hochberg adjustment for multiple testing with a false discovery rate of $10 \%$ was applied $\left(p_{\mathrm{BH}}\right)$.

Results Phospho-T202/T204MAPK, pS118ER $\alpha$ and $\mathrm{pS} 167 \mathrm{ER} \alpha$ were all found to be correlated $\left(p_{\mathrm{BH}}=0.0002\right)$. These markers were not associated with either DFS or OS when controlling for the established clinicopathological factors. Interaction terms between the phospho-markers and treatment strategies for either DFS or OS were not statistically significant $\left(p_{\mathrm{BH}}>0.05\right.$ for all).

Conclusions This PathIES study confirmed previously described associations between the phosphorylation site markers of AKT, MAPK and ER $\alpha$ activity in postmenopausal breast cancer patients. No prognostic correlations between the phosphorylation markers and clinical outcome were found, nor were they predictive for clinical outcomes among patients who switched therapy over those treated with tamoxifen alone.
\end{abstract}

Keywords Breast cancer $\cdot$ Aromatase $\cdot$ Tamoxifen $\cdot$ Prognosis $\cdot$ Biomarkers

Zsolt Szijgyarto and Koen D. Flach have contributed equally to this work.

Electronic supplementary material The online version of this article (https://doi.org/10.1007/s10549-018-05110-x) contains supplementary material, which is available to authorized users.

R. Charles Coombes

c.coombes@imperial.ac.uk

Extended author information available on the last page of the article

\section{Background}

Globally, around 1.7 million new breast cancer cases are diagnosed each year, with over 550,000 patients who succumb to the disease [1]. The majority of cases (70-80\%) are diagnosed with estrogen-receptor alpha (ER $\alpha)$-positive disease and these patients routinely receive endocrine therapeutics as adjuvant treatment following surgery. The most commonly prescribed endocrine therapies in the adjuvant treatment of breast cancer are tamoxifen, or in postmenopausal women aromatase inhibitors (AIs) or sequential treatment of the two. The Intergroup Exemestane Study (IES) 
reported superiority of tamoxifen for 2-3 years followed by AIs, as compared to tamoxifen alone [2]. These findings were confirmed in a recent meta-analysis, which has shown that aromatase inhibitors, given at some point during the treatment (either at the start or after 2-3 years prior tamoxifen exposure) outperforms tamoxifen monotherapy [3].

Currently, it remains elusive whether suitable biomarkers can be identified that would facilitate optimal endocrine treatment selection in the adjuvant treatment of breast cancer, identifying individual patients who would derive selective benefit from tamoxifen, AIs or sequential treatment. Our previous analyses showed that high expression of ER $\beta$ is indicative of no benefit in switching [4]. In contrast, high levels of cell proliferation marker Ki67 indicated selective benefit of AIs over tamoxifen alone [5].

Phosphorylation of ER $\alpha$ at serine residues 118 and 167 by MAPK and AKT, respectively, increases its activity (Online Resource 1) and phosphorylation at these sites has been associated with patient response to tamoxifen $[6,7]$. In contrast, Beelen et al. showed an indication of tamoxifen resistance in postmenopausal breast cancer patients with activated MAPK [8]. No studies to date assessed potential associations of phosphorylation of ER $\alpha$, MAPK or AKT in patients who received both tamoxifen and aromatase inhibitor treatment, and how this compares to tamoxifen alone. To this end, these phospho-modifications as potential biomarkers for selective endocrine therapy benefit were tested, as determined in the IES study. Additionally, immunohistochemistry (IHC) for active MAPK (phosphorylated at threonine residues 202 and 204) as well as AKT (phosphorylated at threonine 308 and serine 473) was undertaken, since these kinases are known to phosphorylate ER $\alpha$. Specifically, MAPK phosphorylates S118ER $\alpha[9,10]$, while AKT stimulates the phosphorylation of S167ER $\alpha$ [11]. Although reports using phospho-specific antibodies have indicated that these post-translational modifications can have an impact on patient's outcome after adjuvant endocrine treatment [6,7], none of these factors has been tested for biomarker potential in the context of a randomised clinical trial, directly comparing outcome after sequential tamoxifen/AI or tamoxifen alone.

Our hypothesis was that activated MAPK and/or AKT pathways - and their downstream impact on ER $\alpha$ phosphorylation at S118 and S167-might be predictive of differential treatment benefit of patients who were treated with tamoxifen alone or who received tamoxifen/exemestane switched therapy.

Our aims in this study were therefore three-fold: firstly, to assess the prognostic significance of the ER $\alpha$ phosphorylation markers in the entire study cohort regardless of treatment received. Secondly, to determine the correlations of the ER $\alpha$ phosphorylation with the respective kinases. Lastly, we aimed to determine whether these markers would indicate selective treatment benefit for patients receiving either tamoxifen alone or for those patients who switched to an AI after 2-3 years of tamoxifen.

\section{Methods}

\section{Patients, data handling and sample collection}

The study design, detailed eligibility criteria and treatment schedules have been previously described [2]. IES was a multicentre, international, randomised, double-blind phase III study, comparing exemestane $25 \mathrm{mg} /$ day to tamoxifen $20 \mathrm{mg} /$ day (30 mg in Denmark) prescribed for 2-3 years in postmenopausal women with $\mathrm{ER}+/$ unknown primary breast cancer who remained disease free after receiving adjuvant tamoxifen therapy for 2 to 3 years [4]. The IES study recruited in total 4724 postmenopausal women from 37 countries (366 centres) between 1998 and 2003 [4]. Formalin-fixed paraffin-embedded (FFPE) tumour samples were retrospectively collected from a subset of centres (PathIES centres $N=89$ ) in accordance with institutional guidelines, ethics requirements and national laws. Of 1506 IES patients managed by PathIES centres, pathological samples from the primary surgery (at least 2 years before randomisation) were collected retrospectively from 1282 women recruited in PathIES centres (85.1\%) [4].

All clinical data used in the analyses were based on the snapshot taken for the most recent IES clinical publication (median follow-up time was 91 months) [12] and the REMARK criteria were employed for data reporting [13].

\section{Immunohistochemistry staining}

Tissue microarrays (TMAs) were constructed using formalin-fixed paraffin-embedded (FFPE) tumour blocks with a total of two cores per tumour. For details on antibodies, staining and scoring, see Online Resource methods section.

\section{Statistical analyses}

Spearman's correlation coefficients $\left(r_{\mathrm{S}}\right)$ were obtained to investigate the associations between the continuous variables of phospho-markers (pT202/T204MAPK, pS118ER $\alpha$ and $\mathrm{pS} 167 \mathrm{ER} \alpha$ ) and ER $\alpha, \mathrm{PR}$ and Ki67. Trend test was used to assess association for ordinal variables (HER2 status, pT308AKT, pT473AKT and other dichotomised phosphomarkers). Chi-squared $\left(\chi^{2}\right)$ test was applied to investigate the association between the baseline characteristics of participants who did and did not provide tumour samples within PathIES participating centres. Disease-free survival (DFS) was defined as time from randomisation to recurrence (local, distant ipsilateral or contralateral) or death without disease relapse (intercurrent death) or censoring to the last date the 
patient was known to be alive and event free. Overall survival (OS) was defined as time from randomisation to date of death or censoring to the last date the patient was known to be alive.

The distributions of DFS and OS according to the subgroups of the phospho-markers were estimated using Kaplan-Meier plots censored at 10 years. Univariate and multivariable Cox proportional hazard $(\mathrm{PH})$ survival models were applied to estimate hazard ratios (HR) for DFS and OS. All univariate and multivariable models met the $\mathrm{PH}$ assumption investigated with Schoenfeld residuals and PH tests.

For each of the phospho-markers (pT308AKT, pT473AKT, pT202/T204MAPK, pS118ER $\alpha$ and pS167ER $\alpha$ ), a CoxPH regression model was fitted in the whole study, regardless of treatment received to assess the prognostic effect on DFS and OS via estimation of hazard ratios and $95 \%$ confidence intervals (CI). CoxPH models were fitted with and without adjusting for pre-specified prognostic factors of the centrally assessed estrogen-receptor status ( $\mathrm{H}$ score), progesterone-receptor status ( $H$ score), Ki67 $(\ln ($ ki67 +0.1$))$, HER2 status, treatment (tamoxifen and exemestane), nodal status, age group, tumour grade and size $(\ln (\operatorname{size}))$. Missing values of the clinicopathological variables were assumed as missing at completely random and therefore not imputed. In the multivariable survival modelling, interaction tests were used to investigate whether there is a differential treatment effect within phospho-markerdefined subgroups.

$P$-values for all statistical tests were two sided and Benjamini-Hochberg adjusted for multiple testing with false discovery rate of $10 \%$. If the Benjamini-Hochberg adjusted $P$-value $\left(p_{\mathrm{BH}}\right)$ was less than 0.05 , the test was considered statistically significant.

\section{Results}

\section{PathIES participants}

Of the 4724 postmenopausal women with ER $\alpha$-positive/ unknown primary breast cancer in IES trial, 1506 were managed in 89 centres participating in PathIES study (Fig. 1; Table 1). These centres recruited 1282 (85\%, 1282/1506) women into PathIES of whom 1036 had phospho-marker data (Fig. 1; Table 1 and Online Resource 4).

\section{Staining and scoring of the phospho-markers}

Representative images of immunostaining for each marker with range of intensity are shown in Fig. 2. Good agreement was found between the independent observers when assessing the expression levels of the phospho-markers

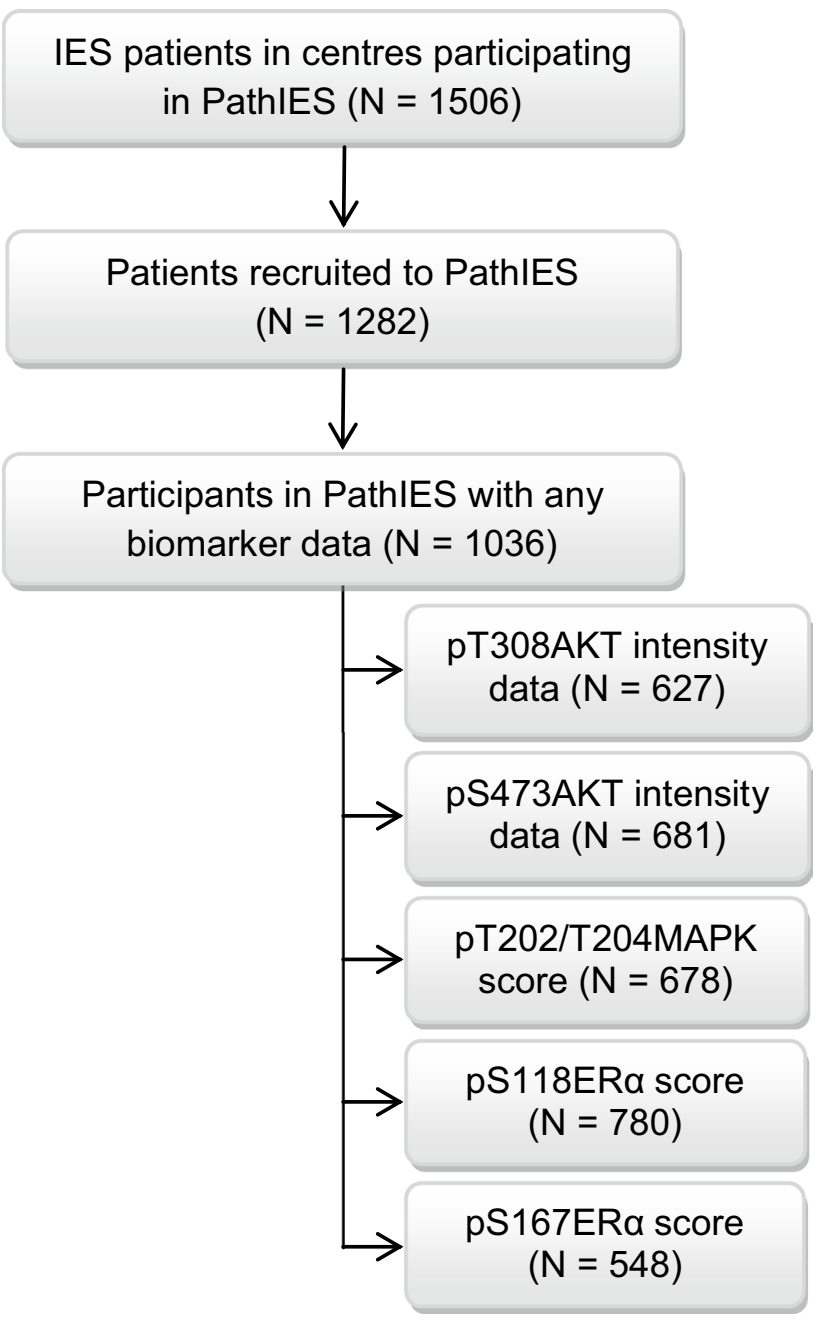

Fig. 1 PathIES participants. Flow chart for PathIES participants with phospho-marker data

(Online Resource 5). Phospho-T308AKT, pS473AKT, pT202/T204MAPK and pS167ER $\alpha$ were detectable in $47.4 \%$ (297/627), 51.1\% (348/681), 46.8\% (316/675) and $52.7 \%(329 / 624)$ of the tumour samples, respectively (Table 2, Online Resource 6, 7). 51.3\% (400/780) of the patients had pS118ER $\alpha$ of $0-40 \%$ and $48.7 \%$ (380/780) presented pS118ER $\alpha$ of $\geq 50 \%$ (Table 2, Online Resource 6, 7). Previous studies regarding pT202/T204MAPK, $\mathrm{pS} 118 \mathrm{ER} \alpha$ and/or $\mathrm{pS} 167 \mathrm{ER} \alpha$ often made use of a negative versus positive cut-off comparison [14-17], a cutoff point we also used for our pT202/T204MAPK and $\mathrm{pS} 167 \mathrm{ER} \alpha$ stainings. For the $\mathrm{pS} 118 \mathrm{ER} \alpha$, however, we used a median based cut-off, yielding well-balanced groups by treatments (Table 2). Additionally, this approach allowed us to prevent the risk of any spuriously significant result associated with the use of optimal cutoff points $[18,19]$. 
Table 1 Baseline characteristics of PathIES participants
PathIES Centres provided tissues $(N=1506)$

Centres not provided tissues

\begin{tabular}{lll}
\hline $\begin{array}{l}\text { Participants } \\
\text { with any BM } \\
\text { scores }\end{array}$ & $\begin{array}{l}\chi^{2} \text { test } \\
\text { within cen- } \\
\text { tre, } p\end{array}$ & $\begin{array}{l}\text { Participants } \\
\text { without tis- } \\
\text { sues/any BM } \\
\text { scores }\end{array}$ \\
$\begin{array}{ll}\text { Total } \\
N=1036\end{array}$ & & $\begin{array}{l}\chi^{2} \text { test with and with- } \\
\text { out tissue provided, } p\end{array}$ \\
\hline$N \quad \%$ & & $\begin{array}{l}\text { Total } \\
N=470\end{array}$ \\
\hline
\end{tabular}

Participants without tissue/any BM scores

Total

$N=3218$

N \%

Treatment

A-exemestane

$534 \quad 51.5$

224

47.7

$246 \quad 52.3$

$1594 \quad 49.5$

B-tamoxifen

$502 \quad 48.5$

0.16

$1624 \quad 50.5$

0.20

Age (years)

\begin{tabular}{|c|c|c|c|c|}
\hline$<60$ & 347 & 33.5 & 145 & 30.9 \\
\hline $60-69$ & 452 & 43.6 & 220 & 46.8 \\
\hline $70+$ & 237 & 22.9 & 105 & 22.3 \\
\hline
\end{tabular}

$1031 \quad 32.0$

$1349 \quad 41.9$

$838 \quad 26.0$

0.20

Grade (G)

$\begin{array}{lrrrr}\text { G1 } & 186 & 18.0 & 86 & 18.3 \\ \text { G2 } & 453 & 43.7 & 180 & 38.3 \\ \text { G3/undifferentiated } & 199 & 19.2 & 79 & 16.8 \\ \text { Not assessable } & 10 & 1.0 & 17 & 3.6 \\ \text { Unknown } & 188 & 18.1 & 108 & 23.0 \\ & & & 0.60^{\mathrm{a}} & \end{array}$

$517 \quad 16.1$

$1354 \quad 42.1$

$645 \quad 20.0$

$\begin{array}{ll}76 & 2.4\end{array}$

$\begin{array}{ll}626 & 19.5\end{array}$

Nodes $(N)$
$\mathrm{N}$

1-3 N+

$447 \quad 43.1$

$371 \quad 35.8$

$\begin{array}{ll}159 & 15.3\end{array}$

$>3 \mathrm{~N}+$

$59 \quad 5.7$

Unavailable

Tumour size $(\mathrm{cm})$

$\begin{array}{lrr}\leq 2 & 596 & 57.5 \\ >2 \text { and } \leq 5 & 393 & 37.9 \\ >5 & 31 & 3.0 \\ \text { Unavailable } & 16 & 1.6\end{array}$

$290 \quad 61.7$

$1899 \quad 59.0$

$152 \quad 32.3$

$7 \quad 1.5$

$1171 \quad 36.4$

$84 \quad 2.6$

$21 \quad 4.5$

0.04

$64 \quad 2.0$

0.33

Histology type Infiltrating ductal

$768 \quad 74.1$

Infiltrating lobular

$160 \quad 15.5$

$108 \quad 10.4$

Other

$0 \quad 0$

0.05

$1171 \quad 55.0$

$911 \quad 28.3$

$444 \quad 13.8$

$92 \quad 2.9$

Unavailable

Previous CT use

$\begin{array}{rc}336 & 71.5 \\ 65 & 13.8 \\ 69 & 14.7 \\ 0 & 0\end{array}$

$2503 \quad 77.8$

$437 \quad 13.6$

$269 \quad 8.4$

$9 \quad 0.2$

No 364 1979 61.5 
Table 1 (continued)

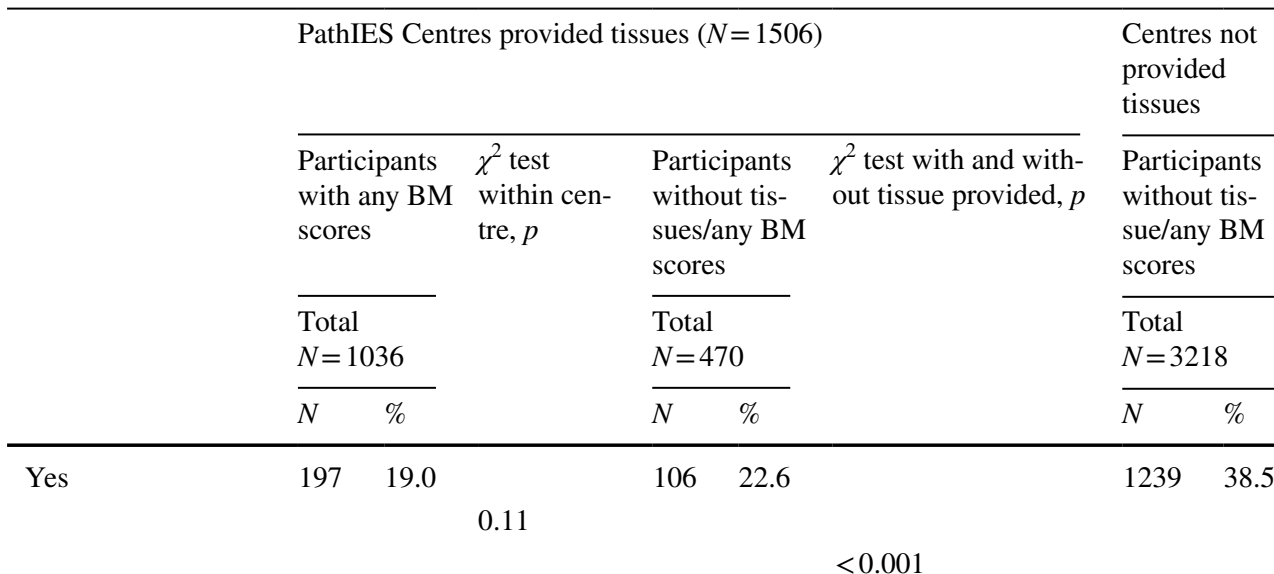

HRT use

$\begin{array}{lrrrrrr}\text { No } & 677 & 65.3 & 111 & 23.6 & 690 & 21.4 \\ \text { Yes } & 323 & 31.2 & 333 & 70.9 & 2477 & 77.0 \\ \text { Unknown } & 36 & 3.5 & 26 & 5.5 & 51 & 1.6\end{array}$

0.005

$<0.001$

Comparison of patient's baseline characteristics who did and did not provide tumour samples within PathIES participating centres

$B M$ biomarker, $C T$ chemotherapy, $H R T$ hormonal replacement therapy

${ }^{\mathrm{a}} \chi^{2}$ test includes G1, G2 and G3/undifferentiated groups only

\section{Correlations between phospho-markers and clinical variables}

As MAPK and AKT signalling cascades are functionally implicated in phosphorylation events on ER $\alpha$, we next tested correlations between all phospho-markers of interest. All phospho-markers of MAPK and ER $\alpha$ (pT202/T204MAPK, $\mathrm{pS} 167 \mathrm{ER} \alpha$ and $\mathrm{pS} 118 \mathrm{ER} \alpha$ ) are positively correlated, albeit moderately [Spearman's correlation coefficients $r_{\mathrm{S}}$ (pT202/ $\mathrm{T} 204 \mathrm{MAPK} / \mathrm{pS} 118 \mathrm{ER} \alpha)=0.62, r_{\mathrm{S}}(\mathrm{pT} 202 / \mathrm{T} 204 \mathrm{MAPK} /$ $\left.\mathrm{pS} 167 \mathrm{ER} \alpha)=0.58, r_{\mathrm{S}}(\mathrm{pS} 167 \mathrm{ER} \alpha / \mathrm{pS} 118 \mathrm{ER} \alpha)=0.59\right]$, yet highly statistically significant $\left(p_{\mathrm{BH}}=0.0002\right.$ for all $)$ (Table 3).

Furthermore, phosphorylation status of both pT308AKT and pS473AKT was associated with high levels of pT202/ T204MAPK, pS167ER $\alpha$ and $\mathrm{pS} 118 \mathrm{ER} \alpha\left(p_{\mathrm{BH}}<0.001\right.$ for all $)$ (Table 4). Similarly, a positive trend was found when comparing pT308AKT and pS473AKT (Table 4). These findings support the known biological connections between ER $\alpha$ phosphorylation status and activity of MAPK and AKT.

The Spearman's correlation of pT202/T204MAPK, $\mathrm{pS} 167 \mathrm{ER} \alpha$ and $\mathrm{pS} 118 \mathrm{ER} \alpha$ with PR status and Ki67 was overall negligible (Table 3). Exploring the distribution of dichotomised phospho-markers by HER2 status, we found more patients with pT308AKT $\left(71 \%, p_{\mathrm{BH}}=0.03\right)$ or $\mathrm{pS} 473 \mathrm{AKT}$ intensity $\left(69 \%, p_{\mathrm{BH}}=0.06\right)$ in the HER2-positive group (Table 5).
The distribution of the dichotomised phospho-markers among the groups of clinical and pathological characteristics is summarised in Online Resource 8, demonstrating that patients with high pT202/T204MAPK $(\geq 10 \%)$, or $\mathrm{pS} 118 \mathrm{ER} \alpha(\geq 50 \%)$ present with lower grade tumours $\left[\mathrm{p}_{\mathrm{BH}}(\mathrm{pT} 202 / \mathrm{T} 204 \mathrm{MAPK})=0.01, p_{\mathrm{BH}}(\mathrm{pS} 118 \mathrm{ER} \alpha)=0.05\right)$ and smaller tumour size $\left(p_{\mathrm{BH}}(\mathrm{pT} 202 / \mathrm{T} 204 \mathrm{MAPK})=0.01\right.$, $\left.p_{\mathrm{BH}}(\mathrm{pS} 118 \mathrm{ER} \alpha)=0.01\right)$. Similarly, patients with high $\operatorname{pS167ER~} \alpha(\geq 10 \%)$ seemed to have smaller tumours $\left(p_{\mathrm{BH}}\right.$ $(\mathrm{pS} 167 \mathrm{ER} \alpha)=0.03]$. Finally, a negative trend was observed between age and pT202/T204MAPK as well as pS118ER $\alpha$; however, these trends were not statistically significant at $10 \%$ false discovery rate: older patients tend to have lower phosphorylation levels of MAPK $\left(p_{\mathrm{BH}}=0.07\right)$ and $\mathrm{ER} \alpha-$ S118 $\left(p_{\mathrm{BH}}=0.07\right)($ Online Resource 8$)$.

\section{Associations of phospho-markers with DFS and OS outcomes}

The potential associations of $\mathrm{pS} 118 \mathrm{ER} \alpha, \mathrm{pS} 167 \mathrm{ER} \alpha$, pT202/T204MAPK, pT308AKT and pS473AKT with outcome, and their relation to therapy were explored. Firstly, Kaplan-Meier estimates for DFS as primary endpoint for IES were analysed for all patients irrespective of therapy. No statistically significant difference in DFS estimates was observed for any of the factors tested (log-rank $p_{\mathrm{BH}}>0.05$ ) (Figs. 3, 4, Online Resource 9, 10, 11). When investigating 


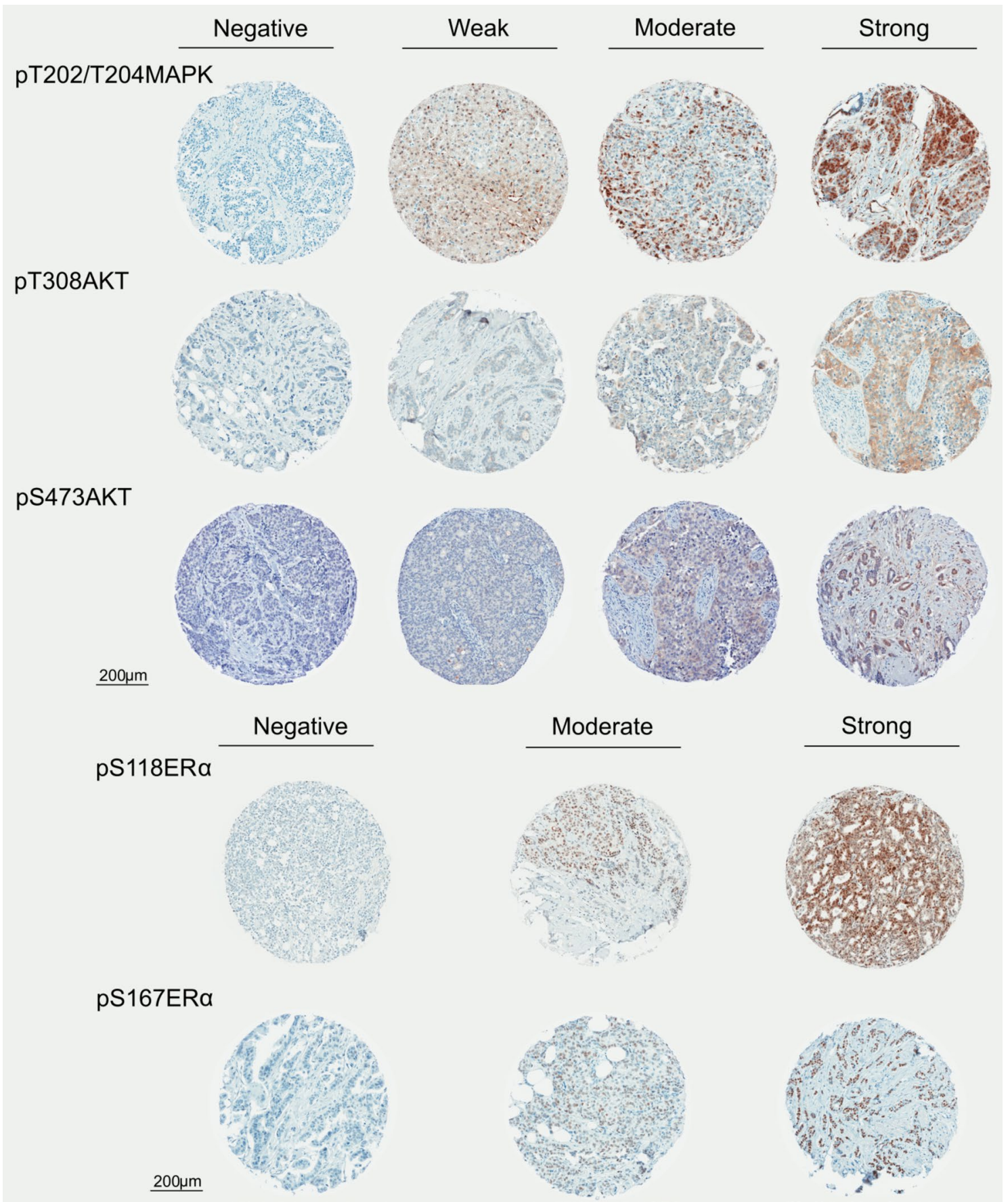

Fig. 2 Immunostaining panel, depicting representative TMA cores. Representative images of immunostaining for each phospho-marker (pT202/ T204MAPK, pT308AKT, pS473AKT, pS118ER $\alpha$ and $\mathrm{pS167ER} \alpha$ ) with range of intensity

how patients with different levels of phospho-markers would respond to tamoxifen and to switched therapy, no statistically significant change in the Kaplan-Meier curves for DFS was revealed for any biomarkers.

The effects of the phosphorylation levels of the markers on overall survival were also explored with Kaplan-Meier curves (Figs. 3, 4, Online Resource 9, 10, 11).
Phosphorylation levels of the biomarkers were not statistically significantly associated with the overall survival outcome of the PathIES participants. Patients with higher levels of pT202/T204MAPK $(\geq 10 \%)$ or $\mathrm{pS} 167 \mathrm{ER} \alpha(\geq 10 \%)$ tend to have better OS than those with pT202/T204MAPK of $0 \%$ (log-rank $\left.p_{\mathrm{BH}}=0.05\right)$ (Fig. 3e) or pS167ER $\alpha$ of $0 \%$ (log-rank $p_{\mathrm{BH}}=0.05$ ) (Fig. 4e); however, none of these associations 
Table 2 Staining results of phospho-markers

\begin{tabular}{|c|c|c|c|c|}
\hline Phospho-markers & $\begin{array}{l}\text { Total } \\
N\end{array}$ & $\begin{array}{l}\text { Tamoxifen } \\
N(\%)\end{array}$ & $\begin{array}{l}\text { Exemestane } \\
N(\%)\end{array}$ & $\begin{array}{l}\text { Test for trend } \\
p_{\mathrm{BH}}\end{array}$ \\
\hline \multicolumn{5}{|c|}{ pT308AKT $(N=627)$} \\
\hline No intensity & 330 & $155(51.7)$ & $175(53.5)$ & \multirow[t]{2}{*}{0.78} \\
\hline With intensity & 297 & $145(48.3)$ & $152(46.5)$ & \\
\hline \multicolumn{5}{|c|}{$\operatorname{pS} 473 \operatorname{AKT}(N=681)$} \\
\hline No intensity & 333 & $160(48.3)$ & $173(52.4)$ & \multirow[t]{2}{*}{0.78} \\
\hline With intensity & 348 & $171(51.7)$ & $177(47.6)$ & \\
\hline \multicolumn{5}{|c|}{ pT202/T204MAPK $(\%)(N=675)$} \\
\hline 0 & 359 & $160(49.8)$ & $199(56.2)$ & \multirow[t]{2}{*}{0.40} \\
\hline$\geq 10$ & 316 & $161(50.2)$ & $155(43.8)$ & \\
\hline \multicolumn{5}{|c|}{$\mathrm{pS} 118 \mathrm{ER} \alpha(\%)(N=780)$} \\
\hline $0-40$ & 400 & $185(49.2)$ & $215(53.2)$ & \multirow[t]{2}{*}{0.43} \\
\hline$\geq 50$ & 380 & $191(50.8)$ & $189(46.8)$ & \\
\hline \multicolumn{5}{|c|}{$\operatorname{pS} 167 \operatorname{ER} \alpha(\%)(N=624)$} \\
\hline 0 & 295 & $133(44.6)$ & $162(49.7)$ & \multirow[t]{2}{*}{0.43} \\
\hline$\geq 10$ & 329 & $165(55.4)$ & $164(50.3)$ & \\
\hline
\end{tabular}

Distribution of the phospho-markers by treatment strategies and the associated trend tests $p_{\mathrm{BH}}$ Benjamini-Hochberg adjusted $p$
Table 3 Positive correlation of pT202/T204MAPK, pS167ER $\alpha$ and $\mathrm{pS} 118 \mathrm{ER} \alpha$

\begin{tabular}{|c|c|c|c|}
\hline & $\begin{array}{l}\text { pT202/T204 } \\
\text { MAPK }(\%)\end{array}$ & $\mathrm{pS} 118 \mathrm{ER} \alpha(\%)$ & $\operatorname{pS} 167 \mathrm{ER} \alpha(\%)$ \\
\hline \multicolumn{4}{|c|}{$\mathrm{pS} 118 \mathrm{ER} \alpha(\%)$} \\
\hline $\mathrm{n}^{\mathrm{a}}$ & 608 & - & - \\
\hline $\mathrm{r}_{\mathrm{S}}^{\mathrm{b}}$ & 0.62 & - & - \\
\hline $\mathrm{p}_{\mathrm{BH}}{ }^{\mathrm{c}}$ & 0.0002 & & \\
\hline \multicolumn{4}{|c|}{$\mathrm{pS} 167 \mathrm{ER} \alpha(\%)$} \\
\hline $\mathrm{n}$ & 571 & 582 & - \\
\hline $\mathrm{r}_{\mathrm{S}}$ & 0.58 & 0.59 & - \\
\hline $\mathrm{p}_{\mathrm{BH}}$ & 0.0002 & 0.0002 & \\
\hline \multicolumn{4}{|c|}{ ER ( $H$ score $)$} \\
\hline $\mathrm{n}$ & 596 & 678 & 540 \\
\hline $\mathrm{r}_{\mathrm{S}}$ & 0.17 & 0.25 & 0.33 \\
\hline $\mathrm{p}_{\mathrm{BH}}$ & 0.0002 & 0.0002 & 0.0002 \\
\hline \multicolumn{4}{|c|}{$\mathrm{PR}(H$ score $)$} \\
\hline $\mathrm{n}$ & 563 & 670 & 528 \\
\hline $\mathrm{r}_{\mathrm{S}}$ & 0.12 & 0.17 & 0.12 \\
\hline $\mathrm{p}_{\mathrm{BH}}$ & 0.005 & 0.0002 & 0.005 \\
\hline \multicolumn{4}{|c|}{ Ki67 (cont.) } \\
\hline $\mathrm{n}$ & 499 & 583 & 461 \\
\hline $\mathrm{r}_{\mathrm{S}}$ & 0.01 & 0.01 & 0.10 \\
\hline $\mathrm{p}_{\mathrm{BH}}$ & 0.79 & 0.79 & 0.05 \\
\hline
\end{tabular}

Spearman's correlation of the phospho-markers and prognostic factors

cont. continuous

${ }^{a}$ - - sample size

${ }^{b} \mathrm{r}_{\mathrm{S}}$-Spearman's correlation coefficient

${ }^{c} \mathrm{p}_{\mathrm{BH}}$-Benjamini-Hochberg adjusted $p$ were statistically significant at $10 \%$ false discovery rate. The association of the levels of the phospho-markers with DFS was next tested in the whole PathIES study sample with CoxPH survival models. None of the phospho-markers was found to be prognostic for DFS either in the univariate or in the multivariable CoxPH models adjusting the effect of each phospho-marker for the prognostic parameters of ER $\alpha, P R$, HER2, Ki67, tumour size and grade, nodal status, age and treatment regimens (Table 6).

When investigating the predictive value of the phosphomarkers with high versus low expression levels on DFS for exemestane over tamoxifen in the entire study sample, none of the biomarkers' expression was statistically significant to predict differential DFS benefit for patients who switched therapy over tamoxifen: the phospho-marker and treatment interaction tests were not statistically significant in the multivariable analyses $\left(p_{\mathrm{BH}}\right.$ corresponding to the interaction test $>0.05$ for all) (Table 6).

Exploring the effect of pT202/T204MAPK on OS in the entire cohort, the crude effect size of pT202/T204MAPK of $\geq 10 \%$ versus $0 \%$ was 0.66 (95\% CI 0.47 to 0.94 ) (Table 7). This would suggest an overall survival benefit among patients with pT202/T204MAPK of $\geq 10 \%$; however, this was not statistically significant after adjusting for multiple testing at $10 \%$ false discovery rate $\left(p_{\mathrm{BH}}=0.06\right)$. The multivariable analyses further demonstrated that this slight association of pT202/T204MAPK with the OS was due to the confounding effect of conventional parameters (HR $0.67,95 \%$ CI 0.33 to $1.34, p_{\mathrm{BH}}=0.29$ ). Similarly, patients (regardless of treatment received) who expressed high level of $\mathrm{pS} 167 \mathrm{ER} \alpha$ seemed to have a better prognosis 
Table 4 Positive correlation of AKT activation with increased phosphorylation levels of MAPK and $\mathrm{ER} \alpha$

\begin{tabular}{|c|c|c|c|c|c|c|c|c|}
\hline & \multicolumn{4}{|c|}{ pT308AKT } & \multicolumn{4}{|c|}{ pS473AKT } \\
\hline & Total & No int. & Int. & Test for trend & Total & No int. & Int. & Test for trend \\
\hline & $N$ & $N(\%)$ & $N(\%)$ & $p_{\mathrm{BH}}$ & $N$ & $N(\%)$ & $N(\%)$ & $p_{\mathrm{BH}}$ \\
\hline \multicolumn{9}{|c|}{ pT202/T204 MAPK (\%) } \\
\hline 0 & 292 & $203(69)$ & $89(33)$ & $<0.001$ & 321 & $195(68)$ & $126(41)$ & $<0.001$ \\
\hline$\geq 10$ & 271 & $90(31)$ & $181(67)$ & & 273 & $93(32)$ & $180(59)$ & \\
\hline \multicolumn{9}{|l|}{$\mathrm{pS} 118 \mathrm{ER} \alpha(\%)$} \\
\hline $0-40$ & 292 & $206(67)$ & $86(31)$ & $<0.001$ & 320 & $195(64)$ & $125(39)$ & $<0.001$ \\
\hline$\geq 50$ & 290 & $102(33)$ & $188(69)$ & & 306 & $112(36)$ & $194(61)$ & \\
\hline \multicolumn{9}{|l|}{$\mathrm{pS} 167 \mathrm{ER} \alpha(\%)$} \\
\hline 0 & 253 & $169(61)$ & $84(32)$ & $<0.001$ & 262 & $148(56)$ & $114(38)$ & $<0.001$ \\
\hline$\geq 10$ & 287 & $110(39)$ & $177(68)$ & & 299 & $114(44)$ & $185(62)$ & \\
\hline \multicolumn{9}{|l|}{ pS473AKT } \\
\hline No intensity & 269 & $187(62)$ & $82(31)$ & $<0.001$ & - & - & - & - \\
\hline Intensity & 298 & $115(38)$ & $183(69)$ & & - & - & - & \\
\hline
\end{tabular}

Distribution of pT202/T204MAPK, pS118ER $\alpha$ and pS167ER $\alpha$ by the groups of phosphorylated AKT and the associated trend tests

int. intensity, $p_{\mathrm{BH}}$ Benjamini-Hochberg adjusted $p$
Table 5 Association of phospho-markers with HER2 status

\begin{tabular}{lllll}
\hline & HER2 & & Test for trend \\
\cline { 2 - 3 } & Total & Negative & Positive & \\
& $N$ & $N(\%)$ & $N(\%)$ & $p_{\text {BH }}$ \\
\hline pT308AKT & & & & \\
No intensity & 224 & $214(55)$ & $10(29)$ & 0.03 \\
Intensity & 202 & $178(45)$ & $24(71)$ & \\
pS473AKT & & & & \\
No intensity & 215 & $203(50)$ & $12(31)$ & 0.06 \\
Intensity & 230 & $203(50)$ & $27(69)$ & \\
pT202/T204MAPK (\%) & & & \\
0 & 257 & $230(55)$ & $27(64)$ & 0.30 \\
$\geq 10$ & 205 & $190(45)$ & $15(36)$ & \\
pS118ER $\alpha(\%)$ & & & & \\
$0-40$ & 290 & $260(53)$ & $30(68)$ & 0.09 \\
$\geq 50$ & 244 & $230(47)$ & $14(32)$ & \\
pS167ER $\alpha(\%)$ & & & & \\
0 & 217 & $195(50)$ & $22(54)$ & 0.62 \\
$\geq 10$ & 217 & $198(50)$ & $19(46)$ & \\
\hline
\end{tabular}

Distribution of the dichotomised phospho-markers by HER2 and the associated trend tests

$p_{\mathrm{BH}}$ Benjamini-Hochberg adjusted $p$

for OS than those with low expression of pS167ER $\alpha$ but this association was not statistically significant (crude HR $0.66,95 \%$ CI 0.46 to $0.94, p_{\mathrm{BH}}=0.06$; adjusted HR $0.58,95 \%$ CI 0.27 to $\left.1.26, p_{\mathrm{BH}}=0.29\right)$ (Table 7). The other markers (pS118ER $\alpha, \mathrm{pT} 308 \mathrm{AKT}$ and pT473AKT) were
Fig. 3 Kaplan-Meier DFS and OS estimates for pT202/T204MAPK. a DFS and e OS estimates by pT202/T204MAPK groups regardless of treatments received. b DFS and $\mathbf{f}$ OS estimates by treatments for patients with pT202/T204MAPK of 0\%. c DFS and g OS estimates by treatments for patients with pT202/T204MAPK intensity of $\geq 10 \%$. Forest plots represent the treatment effects of exemestane versus tamoxifen on d DFS and $\mathbf{h}$ OS in the subgroups of pT202/ T204MAPK as well as in the whole study sample (overall). Hazard ratios were estimated with univariate $\mathrm{CoxPH}$ models. Test for interaction between exemestane versus tamoxifen and pT202/T204MAPK of $\geq 10 \%$ versus $0 \%$ is shown in the forest plots. ( $p$ unadjusted, $p_{B H}$ Benjamini-Hochberg adjusted, Tam tamoxifen, Exem exmestane)

not prognostic for OS in either univariate or multivariable analyses (Table 7).

Interaction tests showed no differential treatment (exemestane over tamoxifen) effect on OS within any of the phospho-markers-defined subgroups $\left(p_{\mathrm{BH}}>0.05\right.$ for all) (Table 7).

In post hoc exploratory analyses of the combinations of factors within the same biological pathway (pT202/ T204MAPK/pS118ER $\alpha, \mathrm{pS} 473 \mathrm{AKT} / \mathrm{pS} 167 \mathrm{ER} \alpha$ and pT308AKT/pS167ER $\alpha$ ), there were no differences observed in DFS (Online Resource 12,13) or OS (Online Resource $12,14)$ outcomes for any of the tested combinations.

Interaction tests between the phospho-markers and treatments demonstrated no predictive value of any pathways investigated either on DFS or on OS among patients treated with exemestane over tamoxifen when adjusting for potential confounders in the entire study sample (all $p_{\mathrm{BH}}$ values corresponding to the interaction test $>0.05$ ). 
a

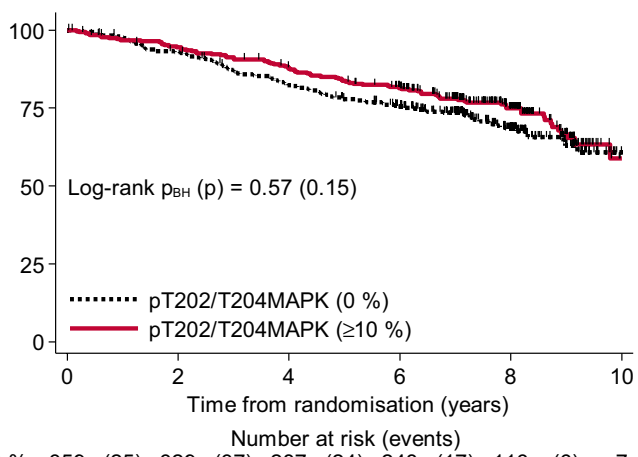

$\begin{array}{lllllllll}0 \% & 359 & \text { (25) } 329 & \text { (37) } 287 & \text { (24) } 248 & \text { (17) } 113 & \text { (6) } 7\end{array}$ $\begin{array}{llllllll}\geq 10 \%: 314 & \text { (17) } 292 & \text { (21) } 267 & \text { (19) } 236 & \text { (15) } 119 & \text { (11) } 10\end{array}$

C

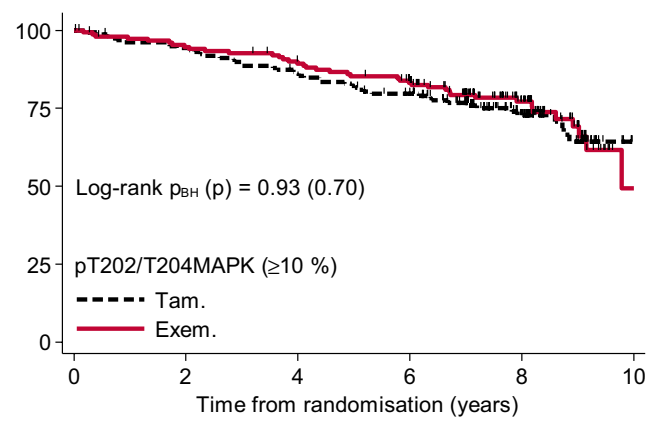

Number at risk (events)

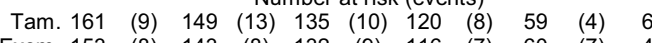

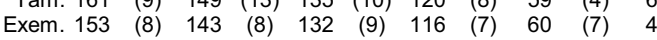

e

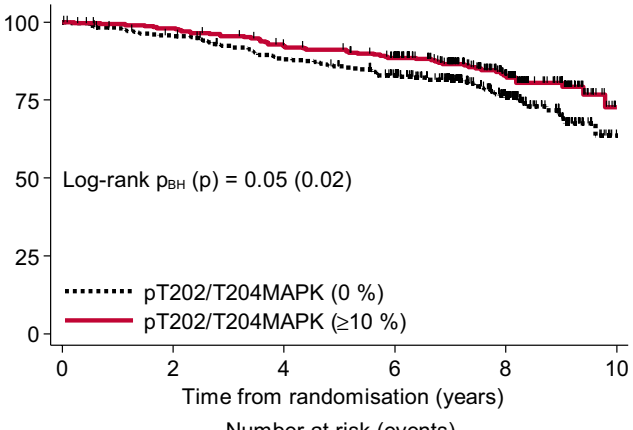

$0 \%: 359 \quad(16) 338 \quad(26) 307 \quad(18) 273$ (16) 125 (8) 7

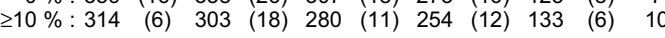

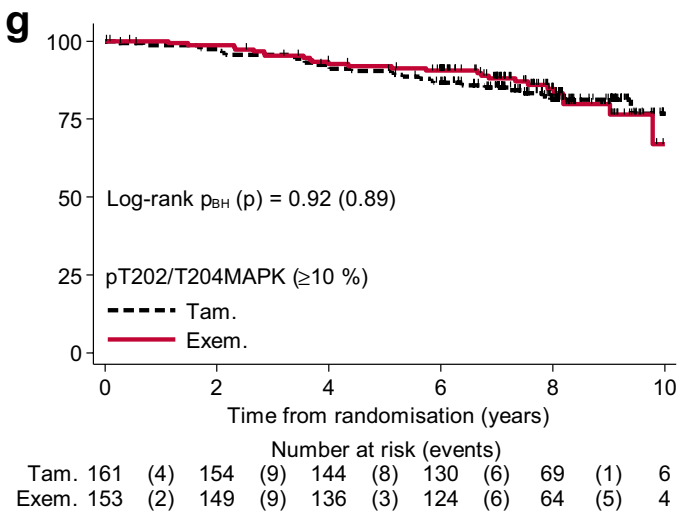

b

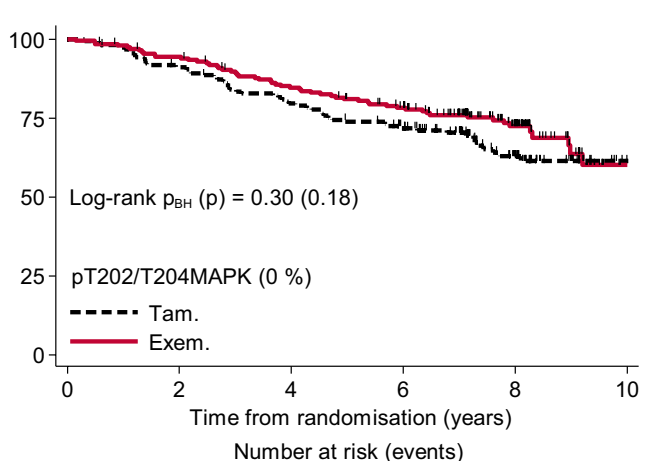

Tam. 160 (14) 143 (18) $124(12) 106 \quad$ (9) $45 \quad$ (1) 3 Exem. 199 (11) $186 \quad(19) \quad 163 \quad(12) \quad 142 \quad$ (8) 68 (5) 4

d

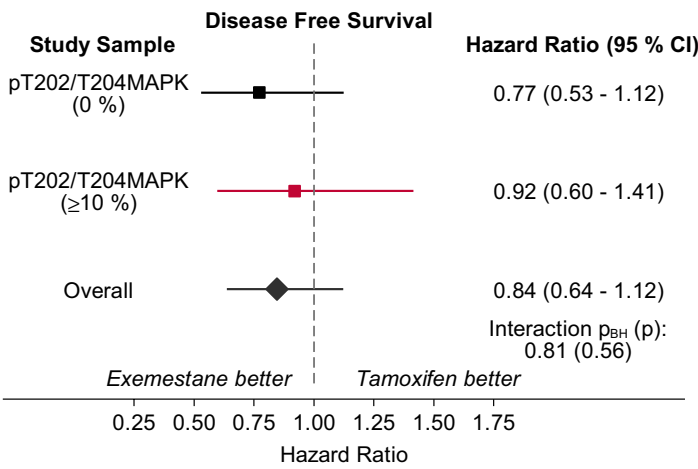

f

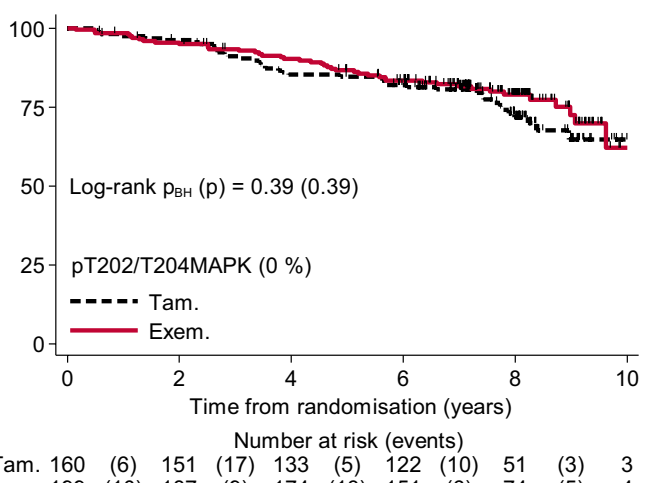
$\begin{array}{rcccccccccc}\text { Tam. } 160 & (6) & 151 & (17) & 133 & (5) & 122 & (10) & 51 & (3) & 3 \\ \text { Exem. } 199 & (10) & 187 & (9) & 174 & (13) & 151 & (6) & 74 & (5) & 4\end{array}$

h

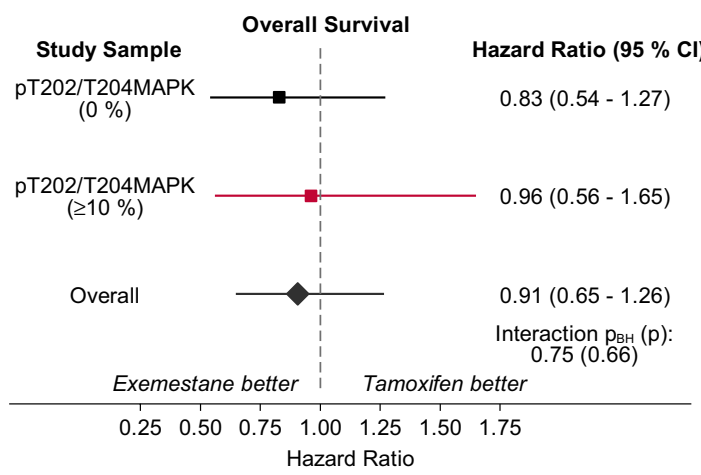


a

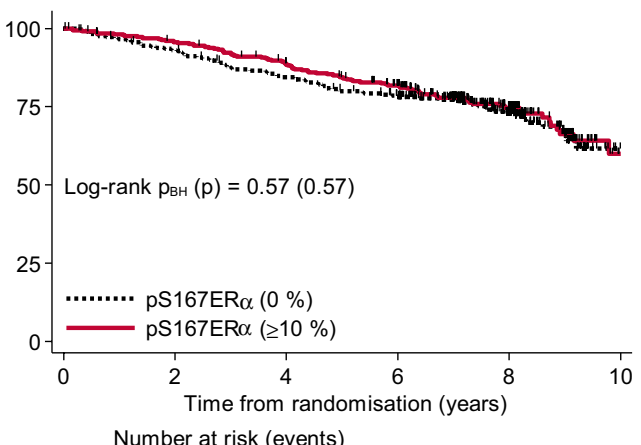

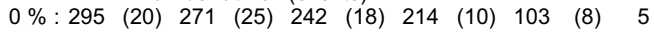

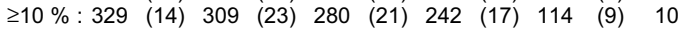

C

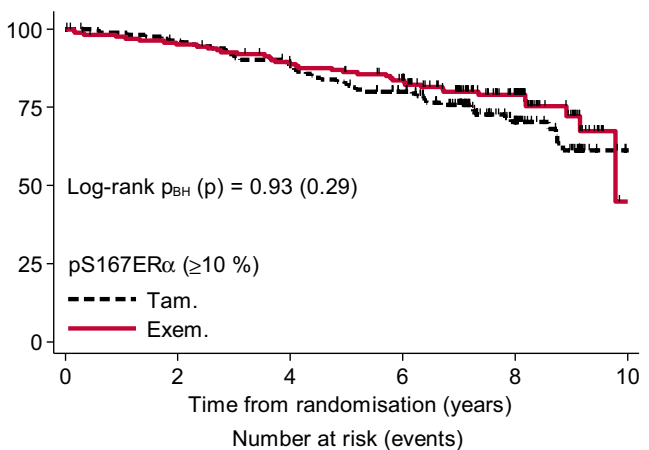
$\begin{array}{rllllllllll}\text { Tam. } 165 & (6) & 156 & (13) & 140 & (13) & 119 & (11) & 51 & (4) & 9 \\ \text { Exem. } 164 & (8) & 153 & (10) & 140 & (8) & 123 & (6) & 63 & (5) & 1\end{array}$

e

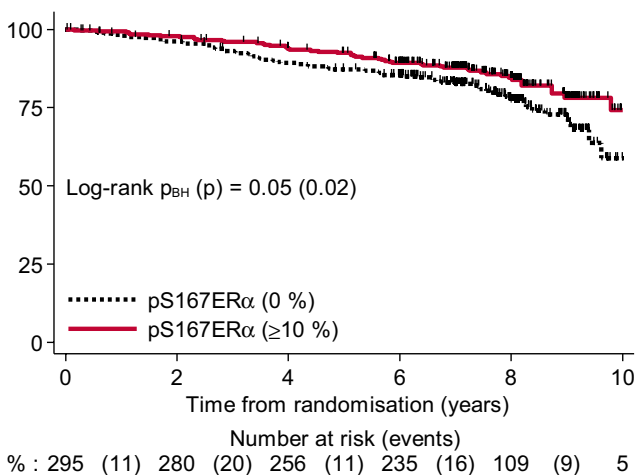
$\begin{array}{llllllll}>10 \% & 329 & \text { (7) } 316 & \text { (13) } & 296 & \text { (14) } 261 & \text { (10) } 131 & \text { (7) } 10\end{array}$

g

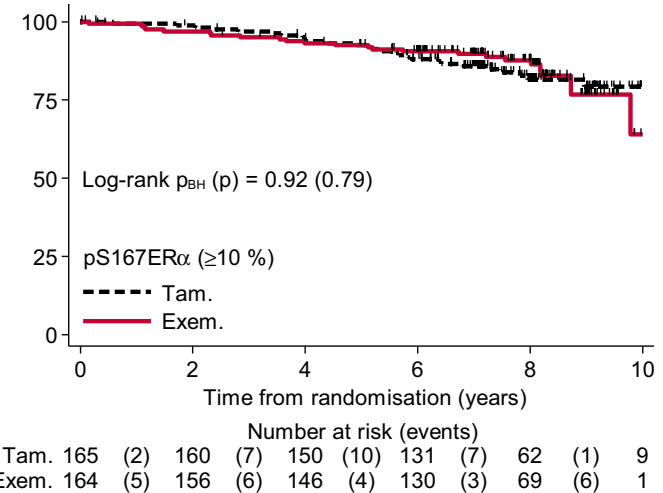

b

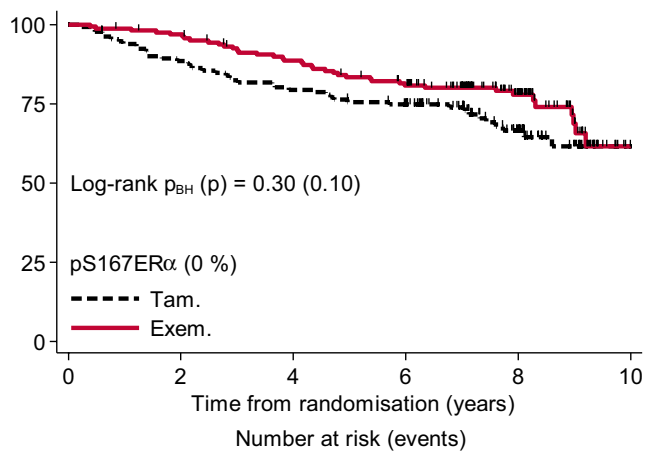

$\begin{array}{lllllllll}\text { Tam. } 133 & (15) & 116 & (12) & 104 & \text { (6) } 94 & \text { (7) } & 41 & \text { (2) } 1\end{array}$

$\begin{array}{lllllllll}\text { Exem. } 162 & \text { (5) } 155 & \text { (13) } 138 & \text { (12) } 120 & \text { (3) } & 62 & \text { (6) } & 4\end{array}$

d

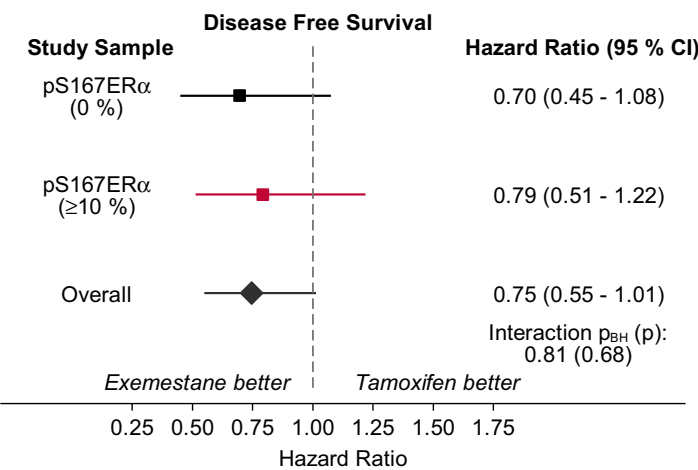

f

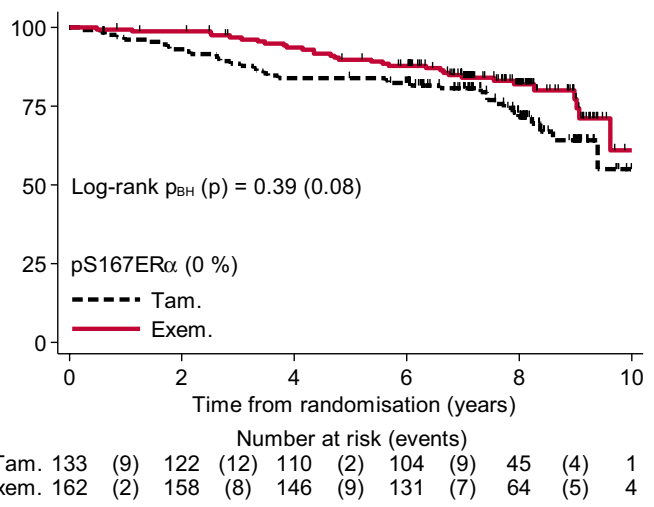

h

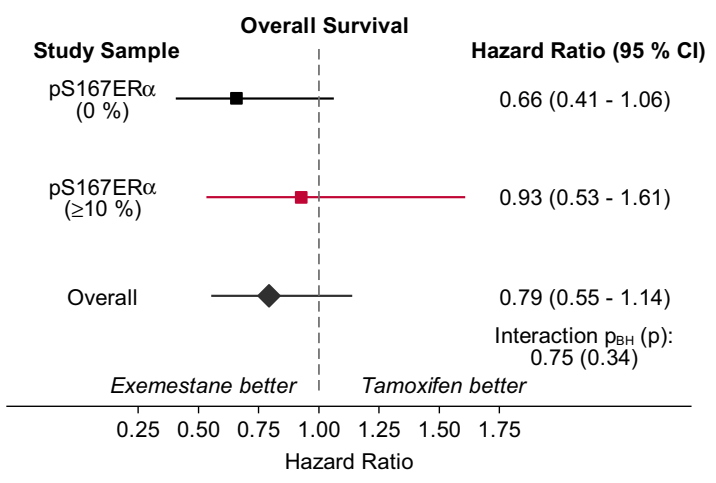


४Fig. 4 Kaplan-Meier DFS and OS estimates for pS167ER $\alpha$. a DFS and e OS estimates by $\mathrm{pS} 167 \mathrm{ER} \alpha$ groups regardless of treatments received. b DFS and f OS estimates by treatments for patients with $\mathrm{pS} 167 \mathrm{ER} \alpha$ of $0 \%$. c DFS and $\mathbf{g}$ OS estimates by treatments for patients with $\mathrm{pS} 167 \mathrm{ER} \alpha$ intensity of $\geq 10 \%$. Forest plots represent the treatment effects of exemestane versus tamoxifen on d DFS and h OS in the subgroups of pT202/T204MAPK as well as in the whole study sample (overall). Hazard ratios were estimated with univariate CoxPH models. Test for interaction between exemestane versus tamoxifen and $\mathrm{pS} 167 \mathrm{ER} \alpha$ of $\geq 10 \%$ versus $0 \%$ is shown in the forest plots. ( $p$ unadjusted, $p_{B H}$ Benjamini-Hochberg adjusted, Tam tamoxifen, Exem exmestane)

\section{Discussion}

In the adjuvant treatment of breast cancer, multiple endocrine therapeutic options are available and current guidelines permit the use of tamoxifen, aromatase inhibitors or a sequential treatment of the two. Therefore, biomarkers are needed to enable optimal endocrine treatment selection. In this study, we used samples from the Intergroup Exemestane Study to evaluate whether there is predictive value of biomarkers in the MAPK/AKT/ER $\alpha$ signalling axis selective for patients receiving either tamoxifen monotherapy or tamoxifen/exemestane sequential treatment. While multiple studies have described an association between tamoxifen response and phosphorylation status of these factors [6-8], such connections are thus far not reported in patients who received both tamoxifen and aromatase inhibitor treatment.

Several studies [14, 20-22], including our own [23-25], have evaluated co-expression of relevant MAPK and AKT pathways with kinases with ER $\alpha$ phosphorylation status; in general, these studies have reported a correlation between $\mathrm{pS} 118 \mathrm{ER} \alpha, \mathrm{pS} 167 \mathrm{ER} \alpha$ and the activation status of respective kinases, i.e. MAPK and AKT. Our current study confirms these findings, further supporting the quality of our dataset.

In the context of PathIES study, the phospho-markers of our interest did not appear to be prognostic for DFS in the entire cohort regardless of treatment received or predictive for this outcome among patients with switched therapy (to exemestane from tamoxifen), over those treated with tamoxifen alone when adjusting for potential confounders.

Phospho-S167ER $\alpha$ has previously been shown to be positively correlated with PR [26] and, by our group, negatively with tumour size [24]. Although it has been reported that $\mathrm{pS} 167 \mathrm{ER} \alpha$ is indicative of good outcome in patients who received adjuvant tamoxifen [24, 26, 27], the present study demonstrated that this biomarker is neither prognostic for DFS or OS nor predictive for these outcomes among PathIES patients managed with exemestane after tamoxifen when controlling for conventional prognostic factors.

In terms of effect on prognosis, several studies have been published examining the effect of pS118ER $\alpha$ where this marker correlates with PR [28] and is negatively correlated with grade [25]. As the association of $\mathrm{pS} 118 \mathrm{ER} \alpha$ with outcome is most profound in pre-menopausal patients [16], any potential inconsistency of our findings with previous reports may be related to differences in menopausal status. Furthermore, our group has previously shown an association
Table 6 Association of the phospho-markers with diseasefree survival (DFS)

\begin{tabular}{|c|c|c|c|c|c|}
\hline \multirow[t]{2}{*}{ Phospho-markers } & \multicolumn{2}{|l|}{ Univariate $\mathrm{CoxPH}$} & \multicolumn{3}{|c|}{ Multivariable $\mathrm{CoxPH}^{\mathrm{a}}$} \\
\hline & HR $(95 \% \mathrm{CI})$ & $\mathrm{p}_{\mathrm{BH}}$ & HR (95\% CI) & $\mathrm{p}_{\mathrm{BH}}$ & Int. ${ }^{\mathrm{b}} \mathrm{p}_{\mathrm{BH}}$ \\
\hline \multicolumn{6}{|l|}{ pT308AKT } \\
\hline No intensity & 1.00 & & 1.00 & & \\
\hline With intensity & $0.89(0.66-1.21)$ & 0.57 & $1.26(0.68-2.35)$ & 0.90 & 0.90 \\
\hline \multicolumn{6}{|l|}{ pS473AKT } \\
\hline No intensity & 1.00 & & 1.00 & & \\
\hline With intensity & $1.09(0.89-1.45)$ & 0.57 & $0.94(0.53-1.66)$ & 0.90 & 0.90 \\
\hline \multicolumn{6}{|c|}{ pT202/T204MAPK (\%) } \\
\hline 0 & 1.00 & & 1.00 & & \\
\hline$\geq 10$ & $0.81(0.61-1.08)$ & 0.57 & $0.88(0.49-1.56)$ & 0.90 & 0.90 \\
\hline \multicolumn{6}{|l|}{$\mathrm{pS} 118 \mathrm{ER} \alpha(\%)$} \\
\hline $0-40$ & 1.00 & & 1.00 & & \\
\hline$\geq 50$ & $0.86(0.65-1.12)$ & 0.57 & $0.65(0.40-1.06)$ & 0.72 & 0.90 \\
\hline \multicolumn{6}{|l|}{$\mathrm{pS} 167 \mathrm{ER} \alpha(\%)$} \\
\hline 0 & 1.00 & & 1.00 & & \\
\hline$\geq 10$ & $0.92(0.67-1.24)$ & 0.57 & $0.96(0.53-1.76)$ & 0.90 & 0.90 \\
\hline
\end{tabular}


Table 7 Association of the phospho-markers with overall survival (OS)

\begin{tabular}{|c|c|c|c|c|c|}
\hline \multirow[t]{2}{*}{ Phospho-markers } & \multicolumn{2}{|l|}{ Univariate CoxPH } & \multicolumn{3}{|c|}{ Multivariable CoxPH ${ }^{\mathrm{a}}$} \\
\hline & HR $(95 \% \mathrm{CI})$ & $p_{\mathrm{BH}}$ & HR $(95 \% \mathrm{CI})$ & $\mathrm{p}_{\mathrm{BH}}$ & Int. ${ }^{\mathrm{b}} p_{\mathrm{BH}}$ \\
\hline \multicolumn{6}{|l|}{ pT308AKT } \\
\hline No intensity & 1.00 & & 1.00 & & \\
\hline With intensity & $0.73(0.50-1.06)$ & 0.16 & $1.55(0.74-3.25)$ & 0.29 & 0.77 \\
\hline \multicolumn{6}{|l|}{ pS473AKT } \\
\hline No intensity & 1.00 & & 1.00 & & \\
\hline With intensity & $0.93(0.66-1.30)$ & 0.66 & $0.69(0.35-1.37)$ & 0.29 & 0.96 \\
\hline \multicolumn{6}{|c|}{ pT202/T204MAPK (\%) } \\
\hline 0 & 1.00 & & 1.00 & & \\
\hline$\geq 10$ & $0.66(0.47-0.94)$ & 0.06 & $0.67(0.33-1.34)$ & 0.29 & 0.77 \\
\hline \multicolumn{6}{|l|}{$\mathrm{pS} 118 \mathrm{ER} \alpha(\%)$} \\
\hline $0-40$ & 1.00 & & 1.00 & & \\
\hline$\geq 50$ & $0.83(0.60-1.14)$ & 0.30 & $0.50(0.27-0.93)$ & 0.14 & 0.96 \\
\hline \multicolumn{6}{|l|}{$\operatorname{pS} 167 \mathrm{ER} \alpha(\%)$} \\
\hline 0 & 1.00 & & 1.00 & & \\
\hline$\geq 10$ & $0.66(0.46-0.94)$ & 0.06 & $0.58(0.27-1.26)$ & 0.29 & 0.82 \\
\hline
\end{tabular}

Univariate and multivariable CoxPH analyses of phospho-markers with OS

$C I$ confidence intervals, $p_{B H}$ Benjamini-Hochberg adjusted $p$

${ }^{a}$ Adjusted for ER, PR, HER2, Ki67, tumour size and grade, nodal status, age and treatment

${ }^{\mathrm{b}}$ Interaction between biomarker and exemestane versus tamoxifen between pT202/T204MAPK and smaller tumour size, and better survival outcome in ER $\alpha$-positive breast cancer patients [24]. The present study appears to confirm the negative associations of both factors (pT202/T204MAPK and $\mathrm{pS} 118 \mathrm{ER} \alpha$ ) with prognostic features such as tumour size, yet no significant association with outcomes was observed in this cohort for either phosphorylation marker.

Activation of the phosphatidyl-inositol-3 kinase pathway as measured by phosphorylation status of components of the protein cascade has been shown to correlate with tamoxifen resistance, while this was not found for its upstream drivers like the presence of a PIK3CA hotspot mutation, or PTEN loss [29, 30]. AKT inhibitors have been shown to extend the duration of response to both tamoxifen and $\mathrm{AI}$ in pre-clinical models [31]. It has also been reported that high AKT activity, as defined by phosphorylation at serine 473 and threonine 308, does not predict for significant benefit from tamoxifen [8]. In this study, the correlations between AKT phosphorylation and poor prognosis in ER $\alpha$-positive patients were not observed, although high expression of its downstream target p-p70S6K had been reported to confer a favourable prognosis in postmenopausal patients [8]. Data in this study which supported the correlations with conventional prognostic factors, AKT phosphorylation, however, showed no independent impact on prognosis in this randomised phase III study population.

\section{Conclusion}

This study of 1036 primary tumours confirms the association between activated AKT, MAPK and ER $\alpha$ phosphorylation status in postmenopausal breast cancer patient, but does not corroborate their prognostic power for DFS or OS in the entire PathIES study, nor their predictive values for these outcomes for patients managed by switched therapy over tamoxifen alone.

Acknowledgements We thank the women who took part in this study, the pathologists, oncologists, nurses and support staff at local sites, and the data managers, trial coordinators and study managers from the Central and Eastern European Oncology Group (Poland: J. Jassem, A. Brociek, (A) Pliszka), the Danish Breast Cancer Group (J. Andersen, (B) Bruun Rasmussen), the European Organisation for the Treatment and Research of Cancer (Netherlands: (C) van de Velde, E. Meershoek, Belgium: R. Paridaens, A. Delorge), the Gruppo Oncologico Nord Ovest, the Gruppo Oncologico Italiano di Ricerca Clinica, the International Breast Cancer Study Group (Switzerland: A. Coates, R. Camler), the International Collaborative Cancer Group (United Kingdom:, K. Mousa, S. Reed, Belgium: (D) Verhoeven, S. Herman), Italian Trials in Medical Oncology (M. Visini), the North West England Group, the Norwegian Breast Cancer Group (P. Lonning), the Yorkshire Breast Group, the Wales Cancer Trials Network, the ICR-CTSU (Lucy Kilburn and Eleftheria Kalaitzaki). We also thank the Breast International Group for their support and the members of the IES steering committee and the PathIES Sub-Committee. The authors would also like to acknowledge the NKI Core Facility Molecular Pathology \& Biobanking (CFMPB) for lab support. 
Author Contributions RCC, WZ, MCUC and JMB contributed to the study design. RCC was the project leader and involved all stages of the study. ZS, KDF, WZ, JMB, MCUC and RCC wrote the manuscript. ZS executed the statistical analyses under supervision of MCUC. KDF and MO performed the immunostaining. Samples were scored by KDF and MO, under supervision of SCL, WZ and JW. RCC, ZS, KDF, WZ, JMB and MCUC performed data interpretation. $\mathrm{CP}$ added supporting clinical information. SA advised on phospho-markers and interpretation. All authors critically read and contributed to the final version of the manuscript.

Funding Research was supported by Cancer Research UK (C37/ A8434) and Pfizer (GA9001DP). RCC received a Cancer Research UK programme Grant for the Division of Cancer at Imperial College London. This study was supported by Imperial Experimental Cancer Medicine Centre, Imperial Biomedical Research Centre and Imperial Cancer Research UK Centre. JMB received a Cancer Research UK programme Grant (C1491/A9895) for The Institute of Cancer Research Clinical Trials and Statistics Unit. MCUC and ZS were supported by the Cancer Research UK Programme grant. RCC and SA were supported by Cancer Research UK (C37/A18784). KDF, SCL and WZ were supported by A Sister's Hope. WZ was supported by KWF Dutch Cancer Society, a Bas Mulder Award from Alpe d'HuZes/KWF and a VIDI grant from the Netherlands Organisation for Scientific Research NWO. SCL received institutional unrestricted research Grant from Amgen, AstraZeneca, Genentech, Roche, Sanofi and Tesaro.

Data Availability The clinical dataset and IHC images analysed during the current study are not publicly available due to ethical legislation.

\section{Compliance with ethical standards}

Conflict of interest SCL reported consultant role paid to institution for Bayer, AstraZeneca, IBM, Novartis and Pfizer. SCL also declared a pro bono advisory role for Cergentis and Philips Health BV. RCC reports speaker engagement fees from Pfizer. All the other authors have declared no conflicts of interest.

Ethics approval Formalin-fixed paraffin-embedded (FFPE) tumour samples with informed consent were retrospectively collected in accordance with institutional guidelines, ethics requirements and national laws. Laws and regulations at the time of tissue collection on consent requirements, collection of archived FFPE samples from patients that were deceased and international sample transfers limited the number of countries that could participate in PathIES. Leeds (East) Research Ethics Committee provided the ethical approval of this study (Ethics reference: 07/H1306/82). The reference number of the tissue bank for PathIES is Onc_CC_12_043.

Open Access This article is distributed under the terms of the Creative Commons Attribution 4.0 International License (http://creativeco mmons.org/licenses/by/4.0/), which permits unrestricted use, distribution, and reproduction in any medium, provided you give appropriate credit to the original author(s) and the source, provide a link to the Creative Commons license, and indicate if changes were made.

\section{References}

1. Ferlay J, Soerjomataram I, Dikshit R, Eser S, Mathers C, Rebelo M, Parkin DM, Forman D, Bray F (2015) Cancer incidence and mortality worldwide: sources, methods and major patterns in GLOBOCAN 2012. Int J Cancer 136(5):E359-E386. https://doi. org/10.1002/ijc.29210
2. Coombes RC, Hall E, Gibson LJ, Paridaens R, Jassem J, Delozier T, Jones SE, Alvarez I, Bertelli G, Ortmann O, Coates AS, Bajetta E, Dodwell D, Coleman RE, Fallowfield LJ, Mickiewicz E, Andersen J, Lonning PE, Cocconi G, Stewart A, Stuart N, Snowdon CF, Carpentieri M, Massimini G, Bliss JM, van de Velde C (2004) A randomized trial of exemestane after two to three years of tamoxifen therapy in postmenopausal women with primary breast cancer. N Engl J Med 350(11):1081-1092. https ://doi.org/10.1056/NEJMoa040331

3. Early Breast Cancer Trialists' Collaborative Group (EBCTCG) DM, Forbes JF, Bradley R, Ingle J, Aihara T, Bliss J, Boccardo F, Coates A, Coombes RC, Cuzick J, Dubsky P, Gnant M, Kaufmann M, Kilburn L, Perrone F, Rea D, Thürlimann B, van de Velde C, Pan H, Peto R, Davies C, Gray R (2015) Aromatase inhibitors versus tamoxifen in early breast cancer: patient-level meta-analysis of the randomised trials. Lancet 386 (10001):1341-1352. https://doi.org/10.1016/s0140 -6736(15)61074-1

4. Speirs V, Viale G, Mousa K, Palmieri C, Reed SN, Nicholas H, Cheang M, Jassem J, Lonning PE, Kalaitzaki E, van de Velde CJ, Rasmussen BB, Verhoeven DM, Shaaban AM, Bartlett JM, Bliss JM, Coombes RC (2015) Prognostic and predictive value of ERbeta1 and ERbeta2 in the Intergroup Exemestane Study (IES)first results from PathIESdagger. Ann Oncol 26(9):1890-1897. https://doi.org/10.1093/annonc/mdv242

5. Viale G, Giobbie-Hurder A, Regan MM, Coates AS, Mastropasqua MG, Dell'Orto P, Maiorano E, MacGrogan G, Braye SG, Ohlschlegel C, Neven P, Orosz Z, Olszewski WP, Knox F, Thurlimann B, Price KN, Castiglione-Gertsch M, Gelber RD, Gusterson BA, Goldhirsch A (2008) Prognostic and predictive value of centrally reviewed Ki-67 labeling index in postmenopausal women with endocrine-responsive breast cancer: results from Breast International Group Trial 1-98 comparing adjuvant tamoxifen with letrozole. J Clin Oncol 26(34):5569-5575. https ://doi.org/10.1200/jco.2008.17.0829

6. Le Romancer M, Poulard C, Cohen P, Sentis S, Renoir JM, Corbo L (2011) Cracking the estrogen receptor's posttranslational code in breast tumors. Endocr Rev 32(5):597-622. https://doi. org/10.1210/er.2010-0016

7. Skliris GP, Nugent ZJ, Rowan BG, Penner CR, Watson PH, Murphy LC (2010) A phosphorylation code for oestrogen receptoralpha predicts clinical outcome to endocrine therapy in breast cancer. Endocr Relat Cancer 17(3):589-597. https://doi.org/10.1677/ erc-10-0030

8. Beelen K, Opdam M, Severson TM, Koornstra RH, Vincent AD, Wesseling J, Muris JJ, Berns EM, Vermorken JB, van Diest PJ, Linn SC (2014) Phosphorylated p-70S6K predicts tamoxifen resistance in postmenopausal breast cancer patients randomized between adjuvant tamoxifen versus no systemic treatment. Breast Cancer Res 16(1):R6. https://doi.org/10.1186/bcr3598

9. Kato S, Endoh H, Masuhiro Y, Kitamoto T, Uchiyama S, Sasaki H, Masushige S, Gotoh Y, Nishida E, Kawashima H, Metzger D, Chambon P (1995) Activation of the estrogen receptor through phosphorylation by mitogen-activated protein kinase. Science 270(5241):1491-1494

10. Bunone G, Briand PA, Miksicek RJ, Picard D (1996) Activation of the unliganded estrogen receptor by EGF involves the MAP kinase pathway and direct phosphorylation. EMBO J 15(9):2174-2183

11. Campbell RA, Bhat-Nakshatri P, Patel NM, Constantinidou D, Ali S, Nakshatri H (2001) Phosphatidylinositol 3-kinase/AKTmediated activation of estrogen receptor alpha: a new model for anti-estrogen resistance. J Biol Chem 276(13):9817-9824. https ://doi.org/10.1074/jbc.M010840200

12. Morden JP, Alvarez I, Bertelli G, Coates AS, Coleman R, Fallowfield L, Jassem J, Jones S, Kilburn L, Lonning PE, Ortmann O, Snowdon C, van de Velde C, Andersen J, Del Mastro L, Dodwell 
D, Holmberg S, Nicholas H, Paridaens R, Bliss JM, Coombes RC (2017) Long-term follow-up of the intergroup exemestane study. J Clin Oncol 35(22):2507-2514. https://doi.org/10.1200/ jco.2016.70.5640

13. McShane LM, Altman DG, Sauerbrei W, Taube SE, Gion M, Clark GM (2005) REporting recommendations for tumor MARKer prognostic studies (REMARK). Nat Clin Pract Urol 2(8):416-422

14. Chen M, Cui YK, Huang WH, Man K, Zhang GJ (2013) Phosphorylation of estrogen receptor alpha at serine 118 is correlated with breast cancer resistance to tamoxifen. Oncol Lett 6(1):118-124. https://doi.org/10.3892/ol.2013.1324

15. Murphy LC, Niu Y, Snell L, Watson P (2004) Phospho-serine-118 estrogen receptor-alpha expression is associated with better disease outcome in women treated with tamoxifen. Clin Cancer Res 10(17):5902-5906. https://doi.org/10.1158/1078-0432. CCR-04-0191

16. Kok M, Holm-Wigerup C, Hauptmann M, Michalides R, Stal O, Linn S, Landberg G (2009) Estrogen receptor-alpha phosphorylation at serine-118 and tamoxifen response in breast cancer. J Natl Cancer Inst 101(24):1725-1729. https://doi.org/10.1093/jnci/djp412

17. Wang B, Jiang H, Ma N, Wang Y (2016) Phosphorylated-p38 mitogen-activated protein kinase expression is associated with clinical factors in invasive breast cancer. SpringerPlus 5(1):934. https://doi.org/10.1186/s40064-016-2636-0

18. Altman DG, Lausen B, Sauerbrei W, Schumacher M (1994) Dangers of using "optimal" cutpoints in the evaluation of prognostic factors. J Natl Cancer Inst 86(11):829-835

19. Royston P, Altman DG, Sauerbrei W (2006) Dichotomizing continuous predictors in multiple regression: a bad idea. Stat Med 25(1):127-141. https://doi.org/10.1002/sim.2331

20. de Leeuw R, Neefjes J, Michalides R (2011) A role for estrogen receptor phosphorylation in the resistance to tamoxifen. Int $\mathbf{J}$ Breast Cancer 2011:232435. https://doi.org/10.4061/2011/232435

21. Bostner J, Karlsson E, Pandiyan MJ, Westman H, Skoog L, Fornander T, Nordenskjold B, Stal O (2013) Activation of Akt, mTOR, and the estrogen receptor as a signature to predict tamoxifen treatment benefit. Breast Cancer Res Treat 137(2):397-406. https://doi.org/10.1007/s10549-012-2376-y

22. Anbalagan M, Rowan BG (2015) Estrogen receptor alpha phosphorylation and its functional impact in human breast cancer. Mol Cell Endocrinol 3:264-272. https://doi.org/10.1016/j. mce.2015.01.016

23. Bartlett JM, A'Hern R, Piper T, Ellis IO, Dowsett M, Mallon EA, Cameron DA, Johnston S, Bliss JM, Ellis P, Barrett-Lee PJ (2013) Phosphorylation of AKT pathway proteins is not predictive of benefit of taxane therapy in early breast cancer. Breast Cancer Res Treat 138(3):773-781. https://doi.org/10.1007/s1054 9-013-2489-y
24. Jiang J, Sarwar N, Peston D, Kulinskaya E, Shousha S, Coombes RC, Ali S (2007) Phosphorylation of estrogen receptor-alpha at Ser167 is indicative of longer disease-free and overall survival in breast cancer patients. Clin Cancer Res 13(19):5769-5776. https ://doi.org/10.1158/1078-0432.ccr-07-0822

25. Sarwar N, Kim JS, Jiang J, Peston D, Sinnett HD, Madden P, Gee JM, Nicholson RI, Lykkesfeldt AE, Shousha S, Coombes RC, Ali $S$ (2006) Phosphorylation of ERalpha at serine 118 in primary breast cancer and in tamoxifen-resistant tumours is indicative of a complex role for ERalpha phosphorylation in breast cancer progression. Endocr Relat Cancer 13(3):851-861. https://doi. org/10.1677/erc.1.01123

26. Yamashita H, Nishio M, Kobayashi S, Ando Y, Sugiura H, Zhang Z, Hamaguchi M, Mita K, Fujii Y, Iwase H (2005) Phosphorylation of estrogen receptor alpha serine 167 is predictive of response to endocrine therapy and increases postrelapse survival in metastatic breast cancer. Breast Cancer Res 7(5):R753-R764. https:// doi.org/10.1186/bcr1285

27. Yamashita H, Nishio M, Toyama T, Sugiura H, Kondo N, Kobayashi S, Fujii Y, Iwase H (2008) Low phosphorylation of estrogen receptor alpha (ERalpha) serine 118 and high phosphorylation of ERalpha serine 167 improve survival in ER-positive breast cancer. Endocr Relat Cancer 15(3):755-763. https://doi.org/10.1677/ erc-08-0078

28. Murphy L, Cherlet T, Adeyinka A, Niu Y, Snell L, Watson P (2004) Phospho-serine-118 estrogen receptor-alpha detection in human breast tumors in vivo. Clin Cancer Res 10(4):1354-1359

29. Karlsson E, Veenstra C, Emin S, Dutta C, Perez-Tenorio G, Nordenskjold B, Fornander T, Stal O (2015) Loss of protein tyrosine phosphatase, non-receptor type 2 is associated with activation of $\mathrm{AKT}$ and tamoxifen resistance in breast cancer. Breast Cancer Res Treat 153(1):31-40. https://doi.org/10.1007/s10549-015-3516-y

30. Beelen K, Opdam M, Severson TM, Koornstra RH, Vincent $\mathrm{AD}$, Wesseling J, Muris JJ, Berns EM, Vermorken JB, van Diest PJ, Linn SC (2014) PIK3CA mutations, phosphatase and tensin homolog, human epidermal growth factor receptor 2, and insulinlike growth factor 1 receptor and adjuvant tamoxifen resistance in postmenopausal breast cancer patients. Breast Cancer Res 16(1):R13. https://doi.org/10.1186/bcr3606

31. Vilquin P, Villedieu M, Grisard E, Ben Larbi S, Ghayad SE, Heudel PE, Bachelot T, Corbo L, Treilleux I, Vendrell JA, Cohen PA (2013) Molecular characterization of anastrozole resistance in breast cancer: pivotal role of the Akt/mTOR pathway in the emergence of de novo or acquired resistance and importance of combining the allosteric Akt inhibitor MK-2206 with an aromatase inhibitor. Int J Cancer 133(7):1589-1602. https://doi.org/10.1002/ ijc. 28182

\section{Affiliations}

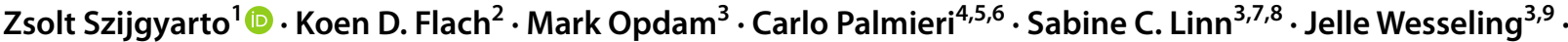 Simak Ali ${ }^{6}$. Judith M. Bliss ${ }^{1} \cdot$ Maggie Chon U. Cheang ${ }^{1} \cdot$ Wilbert Zwart $^{2} \cdot$ R. Charles Coombes ${ }^{6}$}

\author{
Zsolt Szijgyarto \\ Zsolt.Szijgyarto@icr.ac.uk \\ Koen D. Flach \\ k.flach@nki.nl \\ Mark Opdam \\ m.opdam@nki.nl \\ Carlo Palmieri \\ C.Palmieri@liverpool.ac.uk
}

\author{
Sabine C. Linn \\ s.linn@nki.nl \\ Jelle Wesseling \\ j.wesseling@nki.nl \\ Simak Ali \\ simak.ali@imperial.ac.uk \\ Judith M. Bliss \\ Judith.Bliss@icr.ac.uk
}


Maggie Chon U. Cheang

Maggie.Cheang@icr.ac.uk

Wilbert Zwart

w.zwart@nki.nl

1 Clinical Trials and Statistics Unit (ICR-CTSU), Division of Clinical Studies, The Institute of Cancer Research, London SM2 5NG, UK

2 Division of Oncogenomics, Oncode Institute, The Netherlands Cancer Institute, 1066CX Amsterdam, The Netherlands

3 Division of Molecular Pathology, The Netherlands Cancer Institute, Plesmanlaan 121, 1066CX Amsterdam, The Netherlands

4 Department of Molecular and Clinical Cancer Medicine, University of Liverpool, Liverpool L69 3BX, UK
5 Academic Department of Medical Oncology, Clatterbridge Cancer Centre NHS Foundation Trust, Wirral CH63 4JY, UK

6 Department of Cancer and Surgery, Faculty of Medicine, Imperial College London, Du Cane Road, London W12 0NN, UK

7 Department of Medical Onology, The Netherlands Cancer Institute, Plesmanlaan 121, 1066CX Amsterdam, The Netherlands

8 Department of Pathology, University Medical Center Utrecht, Utrecht, The Netherlands

9 Department of Pathology, The Netherlands Cancer Institute, Plesmanlaan 121, 1066CX Amsterdam, The Netherlands 